\title{
Master Narrative Methodology: A Primer for Conducting Structural-Psychological Research
}

\author{
Moin Syed \\ University of Minnesota
}

\author{
Kate C. McLean \\ Western Washington University
}

\begin{abstract}
Objectives: The emphasis placed on individual-level analysis throughout psychological science in general, and diversity science in particular, has left the role of structural factors under-theorized. Moreover, the field suffers from a lack of research methods that fully investigate structural-individual relations. This paper outlines one structural-psychological approach, the master narrative framework, and details various methods for taking social structures into account while still maintaining the focus on the individual. Conclusion: These methods, including event narratives, in-depth interviews, life-script analysis, focus groups, experiments, and conversation analysis, allow for understanding of both the nature and substance of the structures and how individuals interact with them.

Practical significance: Psychology is a discipline that focuses on individual-level behaviors and mental processes. However, those behaviors and mental processes occur within a socially-stratified society, in which some groups have more access to power than others. This paper focuses on research methods that can help bridge the divide between individuals and the social structures in which they live.
\end{abstract}

Keywords: Master narratives, research methods, narrative psychology, diversity science, structural perspectives

Historically, psychological perspectives on diversity, which ostensibly incorporate aspects of structure and context, have not generally been successful in eluding the disciplinary focus on the individual level of analysis. For example, the strong emphasis on implicit bias as a diagnostic marker and point of intervention sends the message that instances of racism and discrimination are rooted in individual attitudes rather than in structural systems of power (Noon, 2018). In recent years various research traditions have begun to coalesce around the concept of diversity science, defined broadly in Plaut's (2010) foundational article as understanding both how and why differences associated with human variability make a difference. Importantly, conceptual models of diversity science have emphasized the need to incorporate structural factors that contour the individual experience, such as power, privilege, and oppression (Miller et al., 2019; Plaut, 2010). This

Moin Syed, Department of Psychology, University of Minnesota. Kate C. McLean, Department of Psychology Western Washington University. This document was typeset using Wiernik's (2019) \#prettypreprint template.

Correspondence regarding this article should be addressed to Moin Syed, Department of Psychology, University of Minnesota, 75 East River Road, Minneapolis, MN 55455, E-mail: moin@umn.edu emphasis notwithstanding, the theoretical approaches employed, and emphasis in design, analysis, and interpretation remains largely at the individual level. Accordingly, there is a great need for psychological perspectives that integrate structural factors to facilitate a structural-psychological approach to diversity science.

The purpose of the present article is to provide a methodological primer on how to conduct psychological research at the structural-psychological level through an examination of theory and research on master narratives, which are culturally shared stories that guide thoughts, beliefs, values, and behaviors (Hammack, 2008; McLean \& Syed, 2015). First, we describe the importance of a structural-psychological perspective, describe the master narrative framework, and elaborate on the benefits of master narratives as a metaframework for diversity science. Second, we describe specific research methods that can be used to investigate master narrative dynamics specifically, or structural-individual relations in general.

\section{How Master Narratives Meet the Call for a Structural-Psychological View}

A sophisticated and productive field of diversity science simply cannot operate solely at the individual 
level. Individual-level psychology is consistent with the colorblind ideological setting of the dominant U.S. approach to the field, which emphasizes individual agency and dispositional factors as the origin for behavior and attitudes (Syed et al., 2018). This ideological setting has given rise to concepts such as resilience, grit, and growth mindset, all of which have been heavily incorporated into the U.S. educational systems. These concepts all point to changing dispositions for achieving success, with no attention directed at racial and economic inequalities, for example, which give rise to their need in the first place. This emphasis is not particularly surprising given psychology's disciplinary focus on the individual level, but as we move seriously towards a psychological science of diversity, it is clear that such a focus simply will not do.

Thus, psychologists will need to engage in interdisciplinary collaborations with fields that have stronger frameworks for studying structural processes (e.g., sociology, social work, ethnic studies) or will need to refine their theoretical models to better accommodate structural factors and facilitate their inclusion in all phases of research. We favor the latter approach, as we believe strongly that psychology has a good deal to offer the broad realm of diversity science and that we need to have a structurally-minded psychology that also prioritizes the types of questions that psychologists tend to ask.

Readers familiar with cultural psychological models may be wondering how our perspective differs from the multitude of available models and perspectives that take systems, power, and context into some consideration (e.g., Hall et al., 2016; Markus \& Kitayama, 1991; Rogoff, 2003; Segall et al., 1998; Shweder, 2000). The difference can be seen most clearly in the recent moves to reconceptualize Bronfenbrenner's ecological systems theory so that history and culture are at the center of the model rather than the periphery (Causadias, 2013; Fish \& Syed, 2018; Juang et al., 2012; Goodnow, 2011; Vélez-Agosto et al., 2017). Placing history and culture at the center and radiating out through the individual highlights how these factors are inseparable from human psychology, rather than seen as "topdown" factors that can be included or excluded at will (see McLean \& Syed, 2015 for elaboration). The implications of this reconfiguration are that structural factors must not only be considered when examining individual psychological phenomena, but that human psycho-

\footnotetext{
${ }^{1}$ Alternative narratives are sometimes also referred to as "counter narratives." There is no real difference between these terms, but we prefer alternative versus counter because
}

logical phenomena are fully intertwined with the structures, which can be "seen" even at the individual level. In other words, structural systems that uphold White supremacy, patriarchy, heteronormativity, and Christianity, to name a few, are not just "contexts" in which individuals develop, but rather are part of the fabric of their everyday lives.

The revised models that place structural factors at the center are helpful for drawing attention to how to think about structural-individual relations generally, but are less useful for providing guidance on the development of specific research questions, hypotheses, and methods. We recently developed the master narrative framework (McLean \& Syed, 2015; see also Hammack; 2008) as one way to address this need (Figure 1). Whereas psychologists have long studied personal narratives - the stories that people tell about their lives and use to construct their identities - they have often treated these stories as more or less self-motivated and personally constructed (Pasupathi \& Wainryb, 2018), consistent with the individual-level focus in the field. In contrast, a master narrative approach draws attention to the culturally shared stories that guide the construction of personal stories. That is, master narratives provide a cultural script that individuals draw upon--often unconsciously--when developing their own personal narratives. These master narratives are imbued with the power structures of a society, and are socialized to maintain the status quo. At the same time, others will actively resist the master narratives to create alternative narratives $^{I}$, scripts that provide a template that pushes against the hegemonic forces of the master narratives and potentially transforms them to accommodate new voices. Whereas incorporating master narratives into individuals' personal narratives is largely done unconsciously, incorporating alternative narratives is often (although not always) a conscious choice. Accordingly, and as we expand on later, individuals who are part of dominant groups will be more likely to align with master narratives whereas individuals from marginalized groups will be more likely to align with alternative narratives. This conceptualization helps provide a structural account for why some individuals do not feel they "fit in" within a society and the associated feelings of stress, which in turn can help identify ways in which to facilitate positive development.

As should be evident in the preceding description of the framework, we conceptualize culture as a higher-

the latter term suggests agency and intention, which is often but not always the case. 


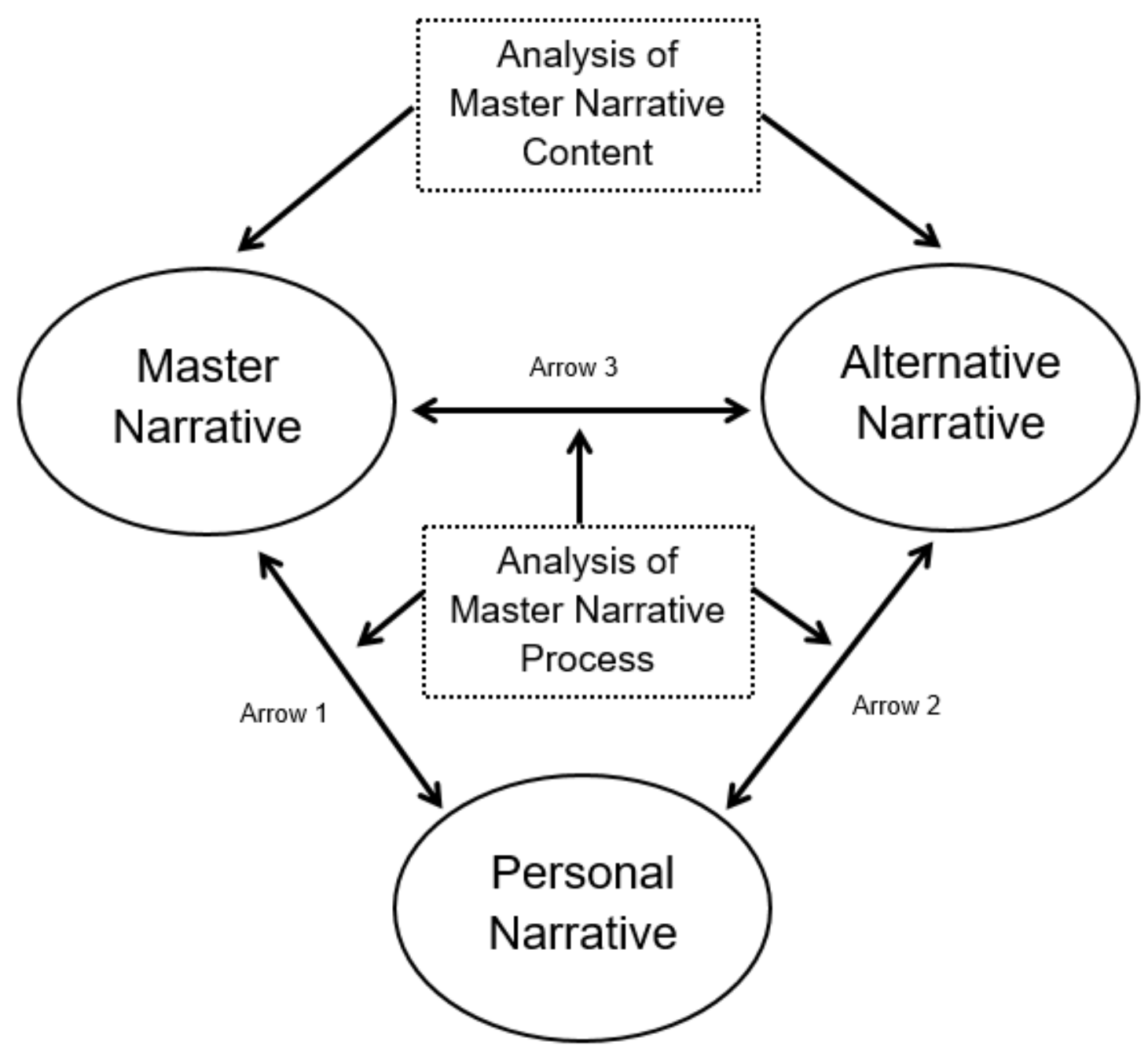

Figure 1. The Master Narrative Framework, as introduced in McLean \& Syed (2015), showing how personal narratives develop within the balance of master narratives and alternative narratives. The bidirectional arrows indicate that individuals, through their personal narratives, both internalize and create/sustain master narratives (arrow 1) and alternative narratives (arrow 2), and that alternative narratives and master narratives exist in relation to one another (arrow 3 ). This modified version of the model shows that the analysis of master narrative content focuses on the master and alternative narratives themselves, whereas the analysis of master narrative process focuses on the arrows between them, or how they dynamically interact.

order category that subsumes structural forms of inequality such as White supremacy and patriarchy. Indeed, master narratives are not value neutral (Syed et al., 2020). Systemic inequality, marginalization, and power are central concepts in understanding how master narratives do or do not create space for personal stories. Thus, master narratives hold great promise for diversity science because attention is given to the kinds of stories that are valued, which align with majority groups who have disproportionate access to power, and the ways in which those valued stories restrict and silence those who hold less structural and narrative power. This perspective aligns with long-standing work in critical race theory, which has emphasized the importance of storytelling from marginalized groups to advance counter-narratives against dominant discourses (e.g., Duncan, 2005; Solorzano \& Yosso, 2002). 


\section{SYED AND MCLEAN}

The master narrative framework has several benefits for a modern diversity science over some other approaches. First, and perhaps most importantly, it provides an alternative model for understanding individual- and group-level variations that is not rooted in a deficit perspective. Understanding personal narratives as a dynamic between competing master and alternative narratives is fundamentally about understanding the power of social groups. Individuals' negotiations with master and alternative narratives is not just a matter of "feeling different," which everyone experiences, but rather focused on shared group-based experiences of difference, which are disproportionately felt by marginalized groups.

A second benefit of the master narrative framework over existing models is that it takes a dynamic view of individuals and the groups of which they are a part. Unlike some models of culture used in diversity science (e.g., individualism and collectivism), which adopt a static, reified, and often stereotypical view of groups (see Gjerde, 2004; Matsumoto, 1999), the master narrative framework emphasizes the dynamic relation between the self and competing narratives. Indeed, within the framework, we attend to both the content of the master, alternative, and personal narratives themselves, which represent relatively rigid and static elements, as well as the processes of how individuals negotiate among the different narratives, which represents the more dynamic elements. As we will elaborate, both are important to understand.

\section{Master Narratives Sound Great....But How Do you Study Them?}

We have found that the concept of master narratives has wide appeal to scholars working in different research areas, especially those who are focused on marginalized communities, but the lack of a clear method for how to incorporate master narratives into their own work acts as a substantial barrier to their uptake. Over the past several years we and our colleagues have conducted numerous empirical studies of master narratives, using diverse methodological approaches, including written narratives, interviews, focus groups, semi-naturalistic conversation, experiments, analysis of cultural products, timelines/life scripts, digital stories, and more. The studies have used both small qualitative designs and large quantitative designs. Moreover, they represent promising methods for examining the interface of social structures and individual psychology, which is exactly what the future of diversity science needs to look like. Additionally, studies of master narratives have focused on a variety of topics that are core to diversity science, such as race, immigration, gender, and sexuality, and have been used for understanding the psychological processes of both marginalized and dominant groups. Indeed, the master narrative framework is broad enough that it can subsume nearly any topic within the realm of diversity science. As such, the methods that we describe in this article can be generalized to projects that do not specifically adopt a master narrative framework, but nevertheless seek to understand structural-individual relations.

Research on topics related to diversity science has relied heavily on either highly-controlled experiments or surveys consisting of self-report rating scales (Plaut, 2010; see also Baumeister et al., 2007). We see great value in both of these methods, and indeed have used them extensively ourselves, yet at the same time they are limited with respect to studying master narratives. "Narrative" will understandably conjure qualitative methods that can be intensive and are out of the scope of what some researchers are willing or able to do. Accordingly, a reader naive to master narrative research would likely conclude that in-depth qualitative methods are required, but in reality that is not the case. In fact, as we discuss, one need not examine narratives at all to conduct research within the master narrative framework (or structural-psychological research more generally). To be sure, many of the methods we describe do use intensive qualitative methods, but others use variations on the experimental and survey methods prevalent in the field.

The broad topic of master narratives can be divided into the dimensions of content and process (see also Galliher et al., 2017). Content pertains to the nature of the master and alternative narratives; how they are defined and conceptualized, what details are included, etc., all of which is relatively static. In contrast, process refers to how individuals relate to the master and alternative narratives, including how they negotiate, resist, internalize and perpetuate them. These are the relatively dynamic elements --how individuals interact with and make sense of the narratives. Any substantive research question pertaining to master narratives may focus on the content, process, or the relations between the two (Figure 1). Determining the content of master and alternative narratives is of course an important and worthwhile endeavor, and we have been strong proponents of descriptive work, which tends to be devalued in academic psychology (Galliher et al., 2017). However, stopping at description of the content loses the power of the master narrative approach. It is through an 


\section{SYED AND MCLEAN}

examination of the process that researchers gain insights into how structural inequities and marginalization become part of individuals' everyday existences, and where the structural-psychological perspective can be fully realized.

In what follows we describe a variety of different methods through which master narratives have specifically been studied, showcasing a range of topics and focal populations (see Table 1 for a summary). What we present here is not intended to be limited to the master narrative domain, but rather the methods can be used and adapted to many other questions and frameworks that prioritize a structurally-focused psychology. For each described method, we first discuss the conceptual approach, and then highlight the specific methods used. We take this approach to illustrate how different types of research questions can better align with different types of methods, attention to which can lead to stronger studies.

\section{Content: Master Narrative Description}

Cultural Products as Description. A core feature of master narratives is that they can be evident in messages communicated through cultural products, such as media, literature, and historical documents, all of which communicate the common and valued stories of a particular culture. For example, McAdams (2006) examined historical narratives (e.g., "slave narratives" see Barrett, 1995), popular fiction and film, religious documents, self-help books, and so on to trace the embeddedness of redemption in U.S. culture, a narrative in which adversity leads to growth, emancipation, and a better life. Similarly, Schwaeble (2019) adopted a governmental/institutional level of analysis, examining master narratives used in policy decisions for sentencing reform of incarcerated individuals through the messages communicated by different interest groups (see also Blount-Hill, 2020).

An important aspect of the master narrative framework, and a consideration that needs to be part of any structural-psychological approach, is an understanding that cultures are both rigid and dynamic. They are rigid because those who hold cultural power invest heavily in maintaining the status quo and they are resistant to change, but they remain dynamic because they can be changed--both by those in power and those who are marginalized. For example, Wolak and Peterson (2020) detail how belief in the American Dream ebbs and flows depending on the current economic situation. Similarly, Gjerde (2004) admonished cultural psychol- ogy, specifically the kind employed in social psychology, for taking an ahistorical approach that treated national cultures as static and unchanging. He argued, rather, that the outward projection of national culture is politically and economically motivated. Indeed, crossnational comparative studies of master narratives (e.g., U.S. and Sweden in Svensson \& Syed, 2019), require a cultural-historical analysis to understand the narratives that emerged and that participants use to structure their personal experiences. Thus, to do this kind of work well might require interdisciplinary partnerships with historians, those in communications studies, or other related disciplines. For example, partnering with a media scholar may also enhance the understanding of how media both shapes master narratives, and can be seen as a product of master narratives (e.g., Breen et al., 2016; Eniglein, 2019; Viola \& Verheul, 2019).

The underlying method of the cultural products approach is content analysis, which is focused on deriving contextualized meaning and the communicative intent of a defined set of texts or other media (Hsieh \& Shannon, 2005). Content analysis is primarily an inductive technique, where researchers do not have pre-determined categories prior to the analysis, although they certainly may have some notions of what to expect or what they are looking for. One benefit of content analysis is that it does not require human participants, and so researchers interested in master narrative content can use this approach if accessing the appropriate population would be difficult. On the other hand, challenges of content analysis include defining an appropriate set of material to analyze and the potentially large amount of materials to sift through (see Pauker et al., 2020). Nevertheless, it is a promising method for understanding master narrative content.

Personal Events as Description. Understanding master narratives as cultural products via content analysis has clear utility, but may also be of relatively less interest to many psychologists who may prefer to glean understandings through people, not products. Individuals' life stories, understood through their personal narratives, can be read with a structural lens to "see" master narratives by unearthing common ways of sharing stories (Blount-Hill, 2020; Eriksson et al., 2020). These common stories provide insights into the available storylines through which individuals in different social positions can create their own personal narrative. For example, Cohler and Hammack (2007) examined three different generations of gay men to understand the available master narratives for framing and understanding personal sexual identity development, finding that the cultural expectations for sexual identity narratives 
SYED AND MCLEAN

Table 1

Overview of Approaches, Methods, and Examples for Examining Master Narrative Content and Process

\begin{tabular}{|c|c|c|c|}
\hline Domain & Approach & Methods & Examples \\
\hline \multirow{4}{*}{$\begin{array}{l}\text { Master } \\
\text { Narrative } \\
\text { Content }\end{array}$} & $\begin{array}{l}\text { Cultural Products as } \\
\text { Description }\end{array}$ & Content analysis & Schwaeble (2019) \\
\hline & $\begin{array}{l}\text { Personal Events as } \\
\text { Description }\end{array}$ & $\begin{array}{l}\text { Event narratives, written } \\
\text { Event narratives, interview }\end{array}$ & $\begin{array}{l}\text { Blackie et al. (2020) } \\
\text { Blount-Hill (2020) }\end{array}$ \\
\hline & $\begin{array}{l}\text { Cultural Events as } \\
\text { Description }\end{array}$ & $\begin{array}{l}\text { Event narratives } \\
\text { Phenomenology } \\
\text { Archival analysis }\end{array}$ & $\begin{array}{l}\text { Adler \& Poulin (2009) } \\
\text { Hammack (2006) } \\
\text { Syed et al. (2020) }\end{array}$ \\
\hline & Life Scripts as Description & Life script task & Wilkinson \& Dunlop (2020) \\
\hline \multirow{4}{*}{$\begin{array}{l}\text { Master } \\
\text { Narrative } \\
\text { Process }\end{array}$} & Process through Deviation & $\begin{array}{l}\text { Event narratives, direct } \\
\text { Event narratives, indirect }\end{array}$ & $\begin{array}{l}\text { McLean et al. (2018) } \\
\text { Svenssson \& Syed (2020) }\end{array}$ \\
\hline & $\begin{array}{l}\text { Process through Group } \\
\text { Reflection }\end{array}$ & $\begin{array}{l}\text { Semi-structured interviews } \\
\text { Modified Twenty Statements } \\
\text { Task } \\
\text { Focus groups }\end{array}$ & $\begin{array}{l}\text { Rogers (2020) } \\
\text { Moffitt et al. (2018) } \\
\text { Bradford \& Syed (2019) }\end{array}$ \\
\hline & Process through Evaluation & Experimental vignettes & McLean, Delker, et al. (2020) \\
\hline & $\begin{array}{l}\text { Process through } \\
\text { Conversations }\end{array}$ & Discourse analysis & McLean, Boggs, et al. (2020) \\
\hline
\end{tabular}

depended on the generation in which one came of age (see also Bower et al., 2019; Weststrate, 2020; Weststrate \& McLean, 2010). In this case, a master narrative analysis revealed how both opportunities and constraints to develop a marginalized identity changed over time. (see also Barsigian et al., 2020).

Taking this approach a step further, one can determine if particular ways of structuring stories are associated with indicators of health. McAdams's (e.g., McAdams et al., 1997) original work on redemption showed that those who were quite high in generativity (i.e., concern for future generations) were more likely to tell redemptive stories compared to those who scored lower. In a sample of Swedish adults' narratives of challenging experiences, Eriksson et al. (2020) examined which narrative structures (of four identified) were associated with well-being, with the assumption that those that were positively associated with well-being were more likely to be master narratives. Finally, McLean, Delker, et al. (2020) found that participants rated the 'authors' of redemptive narrative vignettes as more psychologically healthy than those whose narratives of trauma did not end with a feeling that they had grown from the experience. Collectively, these studies highlight how aligning with the narratives of the dominant forces in society are associated with psychological health. Although this is an individual-level observation, it speaks to the broad power of social structures to facilitate and constrain access to positive health.

The potential methods for understanding master narratives through personal events are varied, but 


\section{SYED AND MCLEAN}

largely rely on collecting individuals' personal narratives, which consists of several different methods (see Adler at el. 2017), with the most common being interviews (Eriksson et al., 2020; Kerrick \& Henry, 2017) or written "event narratives" (e.g., Blackie et al., 2020). Event narratives are relatively brief stories (usually no more than a solid paragraph), which participants write in response to a prompt. The prompt can target a specific type of experience (e.g., turning point, life challenge, experience of discrimination) or life domain (e.g., work, ethnicity, gender). The brevity of these stories allows them to be embedded in a larger survey, thereby compensating the short stories with much larger samples than is possible in interviewing participants. Interested readers should consult Adler et al., (2017), which includes many details and considerations regarding the pros and cons of these methods.

Cultural Events as Description. A more constrained version of the personal event approach is focusing instead on personal experiences of cultural events. In the personal event approach, participants are prompted to share an experience of a certain type, but the precise event they share and when it happened in their lifetime is entirely up to them to select unless constrained by the prompt. In contrast, the cultural event approach specifically prompts for individuals to tell stories about shared cultural events, such as stories about the September 11, 2001 terrorist attacks (Adler \& Poulin, 2009) and the 2008 and 2016 U.S. Presidential Elections (Dunlop et al., 2018; Marin, 2017; Marin \& Leo, 2020). An extension of this approach is to examine how individuals narrate a cultural event that they themselves did not directly experience, such as in Lopez's (2019) study of how Spanish students narrated the "Conquest of America." All of these studies reveal the ways in which master narratives formed around cultural events serve to maintain existing systems of power. For example, the U.S. master narrative of "United we Stand" in the wake of 9/11 facilitated the political and military agenda of those in power while simultaneously minimizing the national and global oppression of Muslims (Alsultany, 2012)

Similar to personal events, cultural events can be studied using event narratives. Additionally, a particularly useful approach for understanding cultural events, especially those that are ongoing versus in the past, is the qualitative approach of phenomenology. Phenomenology focuses on the nature of the experiences of a well-defined group, often in terms of shared psychological or sociocultural experience. For example, Hammack's (2006) work on youth narratives in the context of the ongoing Israeli-Palestinian conflict revealed that the master narratives that informed the adolescents' personal narratives were negatively interdependent. That is, the positivity of the Israeli master narrative was dependent on the suffering within the Palestinian master narrative, providing insights into the challenges of creating an identity within the context of conflict. Given that major cultural events are often well-documented, there could be opportunities for secondary data analysis of existing data. For example, Syed et al. (2020) used the publicly available Immigrant Stories archive to examine Somali-Americans narratives of adaptation. Although not a planned aspect of the analyses, nearly all of the participants discussed the Somali Civil War in their stories, allowing for a serendipitous analysis of a major cultural event.

Life Scripts as Description. A final approach to understanding master narrative content comes from researchers who examine life scripts, or the events that are expected to occur in an individual's life from a particular culture (Berntsen \& Rubin, 2004; see also Anne $\&$ Janssen, 2020). Although this work deals with issues of memory and culture, it tends not to be situated within a narrative framework as are the analyses of personal and cultural events. Nevertheless, examining the culturally expected timetable for major events, and how individuals deviate from them, can be deeply informative of master narratives (Arnett, 2016; McLean, et al., 2018). Moreover, as Hammack (2006) demonstrated in his study of life stories of Israeli and Palenstian youth, personal "life diagrams" can be informative of the master narratives that inform them (see Söderström, 2020, for details on the method).

Unlike the other approaches to master narrative content, there is a very specific method used for the life script approach, which focuses on participants' ratings of different life landmarks (pre-determined or participant generated). For example, participants can be given lists of events (e.g., marriage, high school graduation, childrearing, retirement) to rate how likely they are to occur, or how important they are in a person's life. The bulk of this work has been done by asking about life events for the average person, but we have recently adapted this methodology to target particular types of persons. For example, McLean, Boggs, et al. (2020) asked participants to provide likely life events for the typical man or woman, and to rate a list of normative life events for the likelihood of occurrence and importance for typical men or women. Wilkinson and Dunlop (2020) used a similar approach to examine ethnic-racial life scripts for Asian American, Latinx, and White emerging adults, documenting variations in the nature of the scripts as well as links to ethnic identity 


\section{SYED AND MCLEAN}

and well-being. This approach, which has been underused, can help to understand how different groups may have different cultural expectations for the life course, shedding light on what is considered "normative" and "deviant," as well as an understanding for how certain life events considered normative can be constraining for the marginalized group (e.g., childrearing for women; McLean, Boggs, et al., 2020).

\section{Process: Master Narrative Internalization, Negotia- tion, and Socialization}

Process through Deviation. A fundamental aspect of a structural-psychological analysis is understanding how individuals come to embody and resist the social structures within their own lives. Accordingly, a central process-level focus involves examining individuals' position vis-a-vis the master narrative: are they conforming to it or deviating from it? How is conformity or deviation experienced? And how do others respond to conformity or deviation? Asking about conformity to a master narrative can be tricky given that they are often invisible, especially to those who align with them. In contrast, asking people about how they deviate from master narratives can be quite fruitful. Understanding deviations not only brings insights into potential alternative narratives, but also the master narratives themselves: in describing how one deviates (the alternative narrative), one must also describe what one is deviating from (the master narrative). For example, McLean et al. (2017) asked participants if they had deviated from cultural expectations for their gender. In doing so, they identified different types of master and alternative narratives (content), and through follow-up interviews were able to understand more about how such narratives were experienced and socialized. Several studies taking this general approach have supported the idea that those who deviated from the master narrative were more likely to be in structurally marginalized positions (e.g., McLean et al. 2018).

Using event narratives is likely the most effective approach for understanding deviation, as they prompt for specific episodes of cultural difference, and can be used as a large-sample technique embedded in a larger battery. Importantly, using the term "master narratives" in the prompt would be a mistake, as most participants would not likely understand the intended meaning. Rather, the prompt should ask about a time they felt culturally different from others. For example, in McLean et al. (2018) participants were prompted with, "....Sometimes stories from our lives, or aspects of our lives, don't completely match the storyline that others (society, culture, family, friends, etc.) expect us to have, or what is considered appropriate, normal, or accepted. Have you ever felt that your story diverged from what was considered to be normal, expected, or accepted?...."

In addition to this direct form of prompted event narratives, master narrative deviation can be examined indirectly. Individuals will often discuss deviations and master narrative processes in the context of discussing other topics, especially if the prompts pertain to structural contexts. For example, Svensson and Syed (2020) conducted a U.S./Sweden comparative analysis of master narratives of immigration by examining prompts about ethnicity-related experiences. Similarly, McLean et al. (2017) studied master narratives of gender through an analysis of event narratives asking for "...important autobiographical memory that highlights experiences with sex roles; that is, the roles that men and women should play in the world...." This point about indirect master narratives highlights the ongoing utility of narrative data for secondary data analysis and the importance of data sharing (Meyer, 2017). Researchers who do not have the time, resources, or access to required populations would benefit from access to relevant data for further analysis that was not part of the original intended purpose.

Process through Group Reflection. Master narratives are most centrally about group-based cultural narratives, and the power imbued therein. Thus, it is sensible to ask directly about the groups of interest and how people experience them. The challenge, however, can be getting respondents to provide deep, meaningful responses that provide insights into master narrative processes. In a series of studies of Black, White, and Mixed-race children, Rogers (2020; Rogers \& Meltzoff, 2017; Rogers \& Way, 2018) illuminated various narratives around gender and race that were differentially employed depending on children's identity characteristics by getting them to think about the meaning of their gender, race, and their intersections. A key approach in these studies is getting them to bring their social identities into relief by asking what they think their life would be like if they were a different gender or race. A similar approach was taken up by Way et al. (2008), who asked high school students why they wanted to be identified or not identified with their racial group, and Azmitia et al. (2008), who asked college students if they felt their parents would have treated them differently if they were a different gender. In all cases the interaction between societal and individual representations of groups is facilitated through imagined comparison. 


\section{SYED AND MCLEAN}

The optimal method for getting individuals to reflect on the nature and meaning of their group identities is semi-structured interviews, which allows for necessary follow-up questions and elaborations. However, asking participants directly about the meaning of their group memberships is unlikely to be productive. Approaches that have been effective at prompting deep reflection include, 1) the imagined comparison approach we described previously, in which respondents must consider their position in relation to alternatives; 2) inserting a modified Twenty Statements Test (Kuhn \& McPartland, 1954) into the interview, where participants first provide 20 written responses to the prompt "Who am I?" which the interviewer then uses to ask about what was included, excluded, and why (Juan, 2014; Moffitt et al., 2018); 3) the use of life diagrams (Hammack, 2006; Söderström, 2019), in which participants draw out their life course, signifying notable events or experiences; and 4) scaffolding the interview process to begin with personal stories, moving to parental stories, and then to group stories (Haraldsson \& McLean, 2020). Additionally, Bradford and Syed (2019) used focus groups to investigate transgender participants' beliefs on how both the dominant cisnormative society and the transgender community view gender and identity. The focus group method facilitated robust discussion by allowing participants to build upon each other's comments as well as advance contradictory views, all while taking the pressure off any individual respondent.

Process through Evaluation. All of the approaches discussed heretofore focused on individuals own personal narratives. However, given their social embeddedness, insights into master narrative processes can be gleaned through an understanding of how individuals respond to hearing or reading different types of stories.

Understanding master narratives through evaluation is particularly amenable to experimental methods, especially the use of vignettes that are manipulated to evoke different responses. There is a long history of doing this within the science of behavior change, in terms of testing different "frames" to see how they change individuals' behavior (Langford et al., 2017). Similarly, Destin (2020) and colleagues have tested how various narrative structures can differentially motivate firstgeneration college students. We have recently adopted this approach more directly within the framework of master narratives (Delker et al., 2020; McLean, Delker, et al. 2020) by asking participants to rate vignettes we created and experimentally manipulated in terms of their conformity to master narratives. In doing so we were able to assess how well-received stories of conformity and deviation are and how authors of such stories are perceived (e.g., are they liked, viewed as healthy), providing clear data on the cultural expectation for how particular events are expected to be storied, and how they are likely to be received. Vignettebased methods of master narrative evaluation provide crucial insights into how master narrative may be perpetuated and enforced, constraining the possibilities of those from marginalized backgrounds.

Process through Conversations. The early work on master narratives in psychology focused on the social context of storytelling, specifically how individuals adopt different "positions" around master narratives in natural conversation (e.g., Bamberg, 1997, 2004; Thorne \& McLean, 2003). This approach affords an opportunity to observe actual social negotiation with master and alternative narratives, and where issues of power, oppression, and marginalization are made most vivid (Nasir \& Saxe, 2003).

Naturalistic conversation data are relatively rare in psychological approaches to diversity science, in part because conversations about diversity are difficult to observe spontaneously and/or induce in a natural way (Moffitt \& Syed, 2021). In a series of studies we have made use of a method pioneered by Avril Thorne in her studies of personality dynamics between strangers and friends (Nelson et al., 2011; Korobov \& Thorne, 2005; Thorne, 1987; Thorne et al. 2007). The method consists of three parts. First participants experience some kind of stimulus individually (e.g., survey about personal experiences, about ethnicity-related topics, information about gender-related inequity), which is then followed by a conversation with another person who also experienced the stimulus. Who this "other" person is depends on the research question of the study, but could be a stranger, friend, family member, or even a disguised member of the research team. This conversation typically lasts 10-15 minutes and can be either completely non-directive or participants can be asked to discuss something related to the stimulus they just experienced. Finally, after the conversation each participant is interviewed about the conversation by a research assistant. The conversation is played back so that participants are able to comment on the dynamics of the conversation and research assistants were also able to ask questions about what was happening. This "playback interview" results in a 'meta' analysis of the interpersonal dynamic, including what was felt and what was not said. 
For example, McLean, Boggs, et al. (2020) had mother-adolescent pairs complete a survey about gender that included the life script assessment described previously, and then asked them to talk about the survey for 15 minutes, followed by the playback interviews. Among other insights, the analyses highlighted that whereas the mothers largely adopted a gender equality narrative when in conversation with their children, the playback interviews with the adolescents suggested that they more commonly receive messages consistent with a traditional gender role narrative. Thus, this approach allows us to see the vivid negotiation between personal experiences and master and alternative narratives, including people resisting each other, supporting each other, and how existing power-based societal structures are maintained. Moreover, it demonstrates the strained nature between individual attitudes, which might seek to resist the dominant structures, and actual behaviors that may unwittingly reify them. For readers interested in conversation analysis, much guidance can be found in literatures outside diversity science including the literature on cultural norms and communication (e.g., Lefringhausen et al., 2019) and discourse analysis (Johnstone, 2017).

\section{Summary and Next Steps for Research on Master Narratives}

As is evident from the preceding review, research on master narratives spans a wide range of topic areas and methodological approaches (Table 1). Even within our two broad categories of master narrative content and master narrative process, the study of master narratives can appear, from the outside, as diffuse. A major goal of this article was to bring greater structure to this area of inquiry by laying out different methods for studying master narratives that, while certainly varied, all take seriously the role of structural constraints and opportunities evident with individuals' lives.

As to the future of this line of research, it is essentially limitless. The reality is that this kind of perspective is relatively new in psychology, and while a literature has been accruing, it is still rather thin. This means that there are tremendous opportunities for new advances in our understanding of individual-structural relations. A particularly exciting aspect of master narrative research is its methodological plurality, moving beyond the heavy focus on survey and experimental research seen throughout the literature within the broad field of diversity science. One of our motivations for writing this article was to inspire researchers new to this area (or even to those working in it) to think creatively about new methods they could use to understand psychological phenomena that not only goes beyond the individual level, but considers how the individual level is fundamentally intertwined with the structural level. Indeed, if the conceptualization and analysis does not consider the role of societal power, then it is not a study of master narratives (Syed, 2016). We close our article with an elaboration on this point, given its centrality to the framework.

\section{Coda: Resistance as Fundamental to Master Narratives and Structural-Psychology}

The methods and substantive topics reviewed in this article are diverse, and can appear to be only psychological if not bringing a structural lens. This is critically important: the reason for engaging in this kind of work is due to interest in "seeing" social structures at the psychological level. All of the methods we reviewed--content analysis, event narratives, conversations, etc.--on their own do not have anything to do with taking a structural perspective. Rather, using those methods to understand not only how the structural factors manifest, but also how they are evident within individual attitudes and interpersonal interactions, is the core of the master narrative approach. It is relatively easy--and common--for psychologists to point to racism, sexism, and heteronormativity as important structural factors to consider, but much more difficult--and less common-to get into how they pervade individual psychologies. An understanding of societal power, and how it influences individuals differently is central--necessary--to any structural-psychological approach, and we would argue, to diversity science. As psychologists, we then can ask the questions: how are the structures represented by individuals? How is the structural status quo upheld or challenged? The methods we detailed aim to address these questions.

Although we believe that attention to the content and process of master narratives are both important, methods that allow for an analysis of master narrative processes are necessary to understand one of the most critical aspects of the master narrative framework, which is resistance to master narratives (Gilligan, 1990; Rogers, 2020). Although we argue that master narratives are entrenched in multiple levels of persons and systems, and thus they are very hard to change, transformation is possible, primarily via the route of alternative narratives (Fish \& Counts, 2020). As individuals seek other narrative homes for their life experiences beyond the dominant status quo, if their stories 


\section{SYED AND MCLEAN}

are shared and heard, the status quo may move to embrace those newer narratives, slowly evolving the expectations over time. Indeed, this is one of the core rationales for the central role of narrative within critical race theory (Duncan, 2005).

There are many examples of how narratives of resistance provide powerful catalysts for changing cultures and structures. For example, Rogers (2018) provides a brief history of how resistance exemplifies the role of individual agency in the Eriksonian "transactional relationship of self and society." Rogers showcases the ways that children and adolescents challenge stereotypes about their race and gender as acts of resistance that can serve to change those stereotypes and narratives over time (e.g., Rogers, 2020). Similarly, Mosley et al. (2021) details how activists in the Black

\section{References}

Adler, J. M., Dunlop, W., Fivush, R., Lilgendahl, J. P., Lodi-Smith, J., McAdams, D. P., McLean, K. C., Pasupathi, M., \& Syed, M. (2017). Research Methods for Studying Narrative Identity: A Primer [Preprint]. PsyArXiv. https://doi.org/10.31234/osf.io/cz3q3

Adler, J. M., \& Poulin, M. J. (2009). The Political Is Personal: Narrating 9/11 and Psychological Well-Being. Journal of Personality, 77(4), 903-932._https://doi.org/10.1111/j.14676494.2009.00569.x

Alsultany, E. (2012). Arabs and Muslims in the media: Race and representation after 9/11. NYU Press

Anne, M., \& Janssen, S. M. J. (2020). The Relations between Cultural Life Scripts, Individual Life Stories, and Psychological Distress [Preprint]. PsyArXiv. https://doi.org/10.31234/osf.io/qvksz

Arnett, J. J. (2016). Life Stage Concepts across History and Cultures: Proposal for a New Field on Indigenous Life Stages. $\mathrm{Hu}$ man Development, 59(5), 290-316. https://doi.org/10.1159/000453627

Aronson, B., Meyers, L., \& Winn, V. (2020). "Lies My Teacher [Educator] Still Tells": Using Critical Race Counternarratives to Disrupt Whiteness in Teacher Education. The Teacher Educator, 55(3), $300-322$. https://doi.org/10.1080/08878730.2020.1759743

Azmitia, M., Syed, M., \& Radmacher, K. (2008). On the intersection of personal and social identities: Introduction and evidence from a longitudinal study of emerging adults. New Directions for Child and Adolescent Development, 2008(120), 1-16. https://doi.org/10.1002/cd.212

Bamberg, M. (2004). Form and Functions of 'Slut Bashing' in Male Identity Constructions in15-Year-Olds. Human Development, 47(6), 331-353. https://doi.org/10.1159/000081036

Bamberg, M. G. W. (1997). Positioning between structure and performance. Journal of Narrative \& Life History, 7(1-4), 335-342. https://doi.org/10.1075/jnlh.7.42pos

Barrett, L. (1995). African-American Slave Narratives: Literacy, the Body, Authority. American Literary History, 7(3), 415-442. JSTOR.
Lives Matter movement can share their stories of resistance to prevent continued racial trauma. Others have used the term 'counternarratives' to highlight the active construction of narratives that provide a narrative in opposition to cultural expectations, emphasizing the individual agency to do so (e.g., Aronson et al., 2020; Cohrane-Brown, 2020; Hochman \& SpectorMersel, 2020; Toolis and Hammack, 2015; Miller et al., 2020). And still others have focused on 'asset' narratives to support and lift up those in marginalized positions (Davis et al., 2020). A strong theme throughout these studies of resistance, counternarratives, and asset narratives is the role of personal identity work and exploration, the development of critical consciousness, and the importance of stories that challenge the master narratives.

Barsigian, L. L., Hammack, P. L., Morrow, Q. J., Wilson, B. D. M., \& Russell, S. T. (2020). Narratives of gender, sexuality, and community in three generations of genderqueer sexual minorities. Psychology of Sexual Orientation and Gender Diversity. https://doi.org/10.1037/sgd0000384

Baumeister, R. F., Vohs, K. D., \& Funder, D. C. (2007). Psychology as the Science of Self-Reports and Finger Movements: Whatever Happened to Actual Behavior? Perspectives on Psychological Science, 2(4), 396-403. https://doi.org/10.1111/j.17456916.2007.00051.x

Berntsen, D., \& Rubin, D. C. (2004). Cultural life scripts structure recall from autobiographical memory. Memory \& Cognition, 32(3), 427-442. https://doi.org/10.3758/BF03195836

Blackie, L. E. R., Colgan, J. E. V., McDonald, S., \& McLean, K. C. (20200127). A qualitative investigation into the cultural master narrative for overcoming trauma and adversity in the United Kingdom. Qualitative Psychology https://doi.org/10.1037/qup0000163

Blount-Hill, K-L. (2020). Exploring a Social identity theory of Shared narrative: insights from resident Stories of police contact in Newark, new Jersey, and Cleveland, Ohio. Criminal Justice and Behavior, $\quad 1 \quad-\quad 18$ DOI:olgdr/.o/i/p:stht0.1177/0093854820969751

Bower, K. L., Lewis, D. C., Bermúdez, J. M., \& Singh, A. A. (2019). Narratives of Generativity and Resilience among LGBT Older Adults: Leaving Positive Legacies despite Social Stigma and Collective Trauma. Journal of Homosexuality. [online first] https://doi.org/10.1080/00918369.2019.1648082

Bradford, N. J., \& Syed, M. (2019). Transnormativity and Transgender Identity Development: A Master Narrative Approach. Sex Roles, 81(5-6), 306-325. https://doi.org/10.1007/s11199-018-0992-7

Breen, A. V., McLean, K. C., Cairney, K., \& McAdams, D. P. (2017). Movies, books, and identity: Exploring the narrative ecology of the self. Qualitative Psychology, 4(3), 243-259. https://doi.org/10.1037/qup0000059

Causadias, J. M. (2013). A roadmap for the integration of culture into developmental psychopathology. Development and Psychopathology, 25(4pt2), 1375-1398 https://doi.org/10.1017/S0954579413000679 
Cochrane-Brown, A. (2020). A Qualitative, Counternarrative Study of Rural African American Students' First-Year College Experiences [North Carolina State University]. https://repository.lib.ncsu.edu/bitstream/handle/1840.20/37442/etd.pdf?sequence $=1$

Cohler, B. J., \& Hammack, P. L. (2007). The Psychological World of the Gay Teenager:Social Change, Narrative, and "Normality." Journal of Youth and Adolescence, 36(1), 47-59. https://doi.org/10.1007/s10964-006-9110-1

Davis, S., Reese, L., \& Griswold, C. S. (2020). My Narrative is Not What You Think It Is: Experiences of African Americans in a Doctor of Education Program. International Journal of Doctoral Studies, 15, 199-216.

Delker, B. C., Salton, R., McLean, K. C., \& Syed, M. (2020). Who has to tell their trauma story and how hard will it be? Influence of cultural stigma and narrative redemption on the storying of sexual violence. PLOS ONE, 15(6), e0234201. https://doi.org/10.1371/journal.pone.0234201

Destin, M. (2020). Identity Research That Engages Contextual Forces to Reduce Socioeconomic Disparities in Education. Current Directions in Psychological Science, 29(2), 161-166. https://doi.org/10.1177/0963721420901588

Duncan, G. A. (2005). Critical race ethnography in education: Narrative, inequality, and the problem of epistemology. In A. D. Dixson \& C. K. Rousseau (Eds.), Critical race theory in education (pp. 191-211). New York: Routledge.

Dunlop, W. L., Harake, N., \& Wilkinson, D. (2018). The Cultural Psychology of Clinton and Trump Supporters: A Narrative Approach. Social Psychological and Personality Science, 9(2), 193-204. https://doi.org/10.1177/1948550617732611

Eniglein, J. (2019). "I am East German"-How an East German identity is experienced and defined by the generation born after reunification. Unpublished manuscript, University of Gothenburg. https://gupea.ub.gu.se/handle/2077/62163

Eriksson, P. L., McLean, K. C., \& Frisén, A. (2020). Ta Det Onda Med Det Goda (Accepting the Bad that Comes with the Good) A Cultural Framework for Identity Narratives of Difficult Experiences in Sweden. Identity, 20(3), 157-169. https://doi.org/10.1080/15283488.2020.1781636

Fish, J., \& Counts, P. (2020). "Justice for Native People, Justice for Native Me": Using Digital Storytelling Methodologies to Change the Master Narrative of Native American Peoples. In: K. C. McLean (Ed.), Cultural methodologies in psychology: Describing and transforming cultures. New York: Oxford University Press. https://psyarxiv.com/y2w3v/

Fish, J., \& Syed, M. (2018). Native Americans in Higher Education: An Ecological Systems Perspective. Journal of College Student Development, 59(4), 17.

Galliher, R. V., McLean, K. C., \& Syed, M. (2017). An integrated developmental model for studying identity content in context. Developmental Psychology, 53(11), 2011.

Garcia Coll, C., Lamberty, G., Jenkins, R., McAdoo, H. P., Crnic, K., Wasik, B. H., \& Garcia, H. V. (1996). An Integrative Model for the Study of Developmental Competencies in Minority Children. Child Development, 67(5), 1891-1914. https://doi.org/10.2307/1131600

Gilligan, C. (1990). Joining the resistance: Psychology, politics, girls and women. Ann Arbor: University of Michigan.

Gjerde, P. F. (2004). Culture, Power, and Experience: Toward a Person-Centered Cultural Psychology. Human Development, 47(3), 138-157. https://doi.org/10.1159/000077987
Goodnow, J. J. (2011). Merging cultural and psychological accounts of family contexts. In L. A. Jensen (Ed.), Bridging cultural and developmental approaches to psychology: New syntheses in theory, research, and policy. Oxford University Press.

Hall, G. C. N., Yip, T., \& Zárate, M. A. (2016). On becoming multicultural in a monocultural research world: A conceptual approach to studying ethnocultural diversity. American Psychologist, 71(1), 40-51. https://doi.org/10.1037/a0039734

Hammack, P. L. (2006). Identity, Conflict, and Coexistence: Life Stories of Israeli and Palestinian Adolescents. Journal of Adolescent Research, 21(4), 323-369. https://doi.org/10.1177/0743558406289745

Hammack, P. L. (2008). Narrative and the Cultural Psychology of Identity. Personality and Social Psychology Review, 12(3), 222247. https://doi.org/10.1177/1088868308316892

Haraldsson, K. G., \& McLean, K. C. (2020). "My story is not my own": A qualitative analysis of personal and collective continuity. Manuscript Under Review.

Hsieh, H.-F., \& Shannon, S. E. (2005). Three Approaches to Qualitative Content Analysis. Qualitative Health Research, 15(9), 1277-1288. https://doi.org/10.1177/1049732305276687

Johnstone, B. (2017). Discourse Analysis. John Wiley \& Sons.

Juan, M. J. D. (2014). Intersections of racial/ethnic identity and gender identity among women of color. http://conservancy.umn.edu/handle/11299/167171

Juang, L. P., Syed, M., Cookston, J. T., Wang, Y., \& Kim, S. Y. (2012). Acculturation-based and everyday family conflict in Chinese American families. New Directions for Child and Adolescent Development, 2012(135), 13-34 https://doi.org/10.1002/cd.20002

Kerrick, M. R., \& Henry, R. L. (2017). “Totally in Love”: Evidence of a Master Narrative for How New Mothers Should Feel About Their Babies. Sex Roles, 76(1-2), 1-16. https://doi.org/10.1007/s11199-016-0666-2

Korobov, N., \& Thorne, A. (2006). Intimacy and Distancing: Young Men's Conversations About Romantic Relationships. Journal of Adolescent Research, 21(1), 27-55. https://doi.org/10.1177/0743558405284035

Kuhn, M. H., \& McPartland, T. S. (1954). An Empirical Investigation of Self-Attitudes. American Sociological Review, 19(1), 6876. https://doi.org/10.2307/2088175

Langford, A. T., Larkin, K., Resnicow, K., Zikmund-Fisher, B. J., \& Fagerlin, A. (2017). Understanding the Role of Message Frames on African-American Willingness to Participate in a Hypothetical Diabetes Prevention Study. Journal of Health Communication, 22(8), 647-656. https://doi.org/10.1080/10810730.2017.1339146

Lefringhausen, K., Spencer-Oatey, H., \& Debray, C. (2019). Culture, Norms, and the Assessment of Communication Contexts: Multidisciplinary Perspectives. Journal of Cross-Cultural Psychology, 50(10), 1098-1111. https://doi.org/10.1177/0022022119889162

Lopez, C., Carretero, M., \& Rodriguez-Moneo, M. (2014). Telling a national narrative that is not your own. Does it enable critical historical consumption? Culture \& Psychology, 20(4), 547-571. https://doi.org/10.1177/1354067X14554156

Marin, K. A. (2017). Meaning-Making in Emerging Adults' Narratives About the 2008 U.S. Presidential Election: An Intersection of History, Development, and Self. Emerging Adulthood, 5(6), 379-391. https://doi.org/10.1177/2167696817698879 
Marin, K. A., \& Leo, T. R. (2020). Emerging adults' narratives about the 2016 U.S. Presidential Election: An examination of meaning-making strategies and the role of development. Qualitative Psychology, 7(3), 306-325. https://doi.org/10.1037/qup0000159

Markus, H. R., \& Kitayama, S. (1991). Culture and the self: Implications for cognition, emotion, and motivation. Psychological Review, 98(2), 224-253. https://doi.org/10.1037/0033295X.98.2.224

Matsumoto, D. (1999). Culture and self: An empirical assessment of Markus and Kitayama's theory of independent and interdependent self-construals. Asian Journal of Social Psychology, 2(3), 289-310. https://doi.org/10.1111/1467-839X.00042

McAdams, D. P. (2006). The redemptive self: Stories Americans live by. Oxford University Press. https://doi.org/10.1093/acprof:oso/9780195176933.001.0001

McAdams, D. P., Diamond, A., de St. Aubin, E., \& Mansfield, E. (1997). Stories of commitment: The psychosocial construction of generative lives. Journal of Personality and Social Psychology, 72(3), 678-694. _ https://doi.org/10.1037/00223514.72.3.678

McLean, K. C., Boggs, S., Haraldsson, K., Lowe, A., Fordham, C., Byers, S., \& Syed, M. (2020). Personal identity development in cultural context: The socialization of master narratives about the gendered life course. International Journal of Behavioral Development, 44(2), 116-126.

McLean, K. C., Delker, B. C., Dunlop, W. L., Salton, R., \& Syed, M. (2020). Redemptive Stories and Those Who Tell Them are Preferred in the U.S. Collabra: Psychology, 6(1), 39. https://doi.org/10.1525/collabra.369

McLean, K. C., Lilgendahl, J. P., Fordham, C., Alpert, E., Marsden, E., Szymanowski, K., \& McAdams, D. P. (2018). Identity development in cultural context: The role of deviating from master narratives. Journal of Personality, 86(4), 631-651. https://doi.org/10.1111/jopy.12341

McLean, K. C., Shucard, H., \& Syed, M. (2017). Applying the master narrative framework to gender identity development in emerging adulthood. Emerging Adulthood, 5(2) 93-105.

McLean, K. C., \& Syed, M. (2015). Personal, Master, and Alternative Narratives: An Integrative Framework for Understanding Identity Development in Context. Human Development, 58(6), 318-349. https://doi.org/10.1159/000445817

Meyer, M. N. (2018). Practical Tips for Ethical Data Sharing. Advances in Methods and Practices in Psychological Science, 1(1), 131-144. https://doi.org/10.1177/2515245917747656

Miller, A. L., Stern, C., \& Neville, H. (2019). Forging diversityscience-informed guidelines for research on race and racism in psychological science. Journal of Social Issues, 75(4), 1240 1261. https://doi.org/10.1111/josi.12356

Miller, R., Liu, K., \& Ball, A. F. (2020). Critical Counter-Narrative as Transformative Methodology for Educational Equity. Review of Research in Education, 44(1), 269-300. https://doi.org/10.3102/0091732X20908501

Moffitt, U., Juang, L. P., \& Syed, M. (2018). Being both German and Other: Narratives of contested national identity among white and Turkish German young adults. British Journal of Social Psychology, 57(4), 878-896. https://doi.org/10.1111/bjso.12268

Mosley, D. V., Hargons, C. N., Meiller, C., Angyal, B., Wheeler, P., Davis, C., \& Stevens-Watkins, D. (2021). Critical consciousness of anti-Black racism: A practical model to prevent and resist racial trauma. Journal of Counseling Psychology, 68(1), 1-16. https://doi.org/10.1037/cou0000430
Nasir, N. S., \& Saxe, G. B. (2003). Ethnic and Academic Identities: A Cultural Practice Perspective on Emerging Tensions and Their Management in the Lives of Minority Students. Educational Researcher, 32(5),

14-18. https://doi.org/10.3102/0013189X032005014

Nelson, P. A., Thorne, A., \& Shapiro, L. A. (2011). I'm Outgoing and She's Reserved: The Reciprocal Dynamics of Personality in Close Friendships in Young Adulthood. Journal of Personality, 79(5), 1113-1148._ https://doi.org/10.1111/j.1467_ 6494.2011.00719.x

Noon, M. (2018). Pointless Diversity Training: Unconscious Bias, New Racism and Agency. Work, Employment and Society, 32(1), 198-209. https://doi.org/10.1177/0950017017719841

Pasupathi, M., \& Wainryb, C. (2018). Remembering good and bad times together: Functions of collaborative remembering. In: A. J. Barnier, C.B. Harris, J. Sutton, M. L. Meade, \& P. Van Bergen (Eds.), Collaborative remembering: Theories, research, and applications (pp. 261-279). Oxford University Press.

Pauker, K., Lamer, S. A., Ansari, S., Weisbuch, M. (2020). Cultural Snapshots: Identifying Cultural Patterns that Influence Implicit Racial Bias. To paper in K. C. McLean (Ed.) Cultural Methodologies in Psychology. New York: Oxford Press.

Plaut, V. C. (2010). Diversity Science: Why and How Difference Makes a Difference. Psychological Inquiry, 21(2), 77-99. https://doi.org/10.1080/10478401003676501

Rogers, L. O. (2018). Who Am I, Who Are We? Erikson and a Transactional Approach to Identity Research. Identity, 18(4), 284-294. https://doi.org/10.1080/15283488.2018.1523728

Rogers, L. O. (2020). "I'm Kind of a Feminist": Using Master Narratives to Analyze Gender Identity in Middle Childhood. Child Development, 91, 179-196. https://doi.org/10.1111/cdev.13142

Rogers, L. O., \& Meltzoff, A. N. (2017). Is gender more important and meaningful than race? An analysis of racial and gender identity among Black, White, and mixed-race children. Cultural Diversity and Ethnic Minority Psychology, 23(3), 323-334. https://doi.org/10.1037/cdp0000125

Rogers, L. O., \& Way, N. (2018). Reimagining Social and Emotional Development: Accommodation and Resistance to Dominant Ideologies in the Identities and Friendships of Boys of Color. Human Development, 61(6), 311-331. https://doi.org/10.1159/000493378

Rogoff, B. (2003). The Cultural Nature of Human Development. Oxford University Press.

Schwaeble, K. L. (n.d.). Story Telling by State: Using the Narrative Policy Framework (NPF) to Study the Universality of Mandatory Sentencing Reform Narratives. Working paper, retrieved from https://www.ippapublicpolicy.org/file/paper/5cfefled91d48.pdf.

Segall, M. H., Lonner, W. J., \& Berry, J. W. (1998). Cross-Cultural Psychology as a Scholarly Discipline. American Psychologist, 53(10), 1101-1110. https://doi.org/10.1037/0003066X.53.10.1101

Shweder, R. A. (2000). The psychology of practice and the practice of the three psychologies. Asian Journal of Social Psychology, 3(3), 207-222. https://doi.org/10.1111/1467-839X.00065

Söderström, J. (2020). Life diagrams: A methodological and analytical tool for accessing life histories. Qualitative Research, 20(1), 3-21.https://doi.org/10.1177/1468794118819068

Solórzano, D. G., \& Yosso, T. J. (2002). Critical Race Methodology: Counter-Storytelling as an Analytical Framework for Education Research. Qualitative Inquiry, 8(1), 23-44. https://doi.org/10.1177/107780040200800103 


\section{SYED AND MCLEAN}

Svensson, Y., \& Syed, M. (2019). Linking self and society: Identity and the immigrant experience in two macro-contexts. Journal of Applied Developmental Psychology, 64, 101056. https://doi.org/10.1016/j.appdev.2019.101056

Syed, M., Fish, J., Hicks, J., Kathawalla, U.-K., \& Lee, E. (2019). Somali Migration to the U.S.: Understanding Adaptation through Digital Stories [Preprint]. PsyArXiv. https://doi.org/10.31234/osf.io/c6q72

Syed, M., Pasupathi, M, \& McLean, K. C. (2020). Master narratives, ethics, and morality. In L. A. Jensen (Ed.), The Oxford handbook of moral development: An interdisciplinary perspective (pp. 500-515). New York: Oxford University Press.

Thorne, A. (1987). The press of personality: A study of conversations between introverts and extraverts. Journal of Personality and Social Psychology, 53(4), 718-726. https://doi.org/10.1037/0022-3514.53.4.718

Thorne, A., Korobov, N., \& Morgan, E. M. (2007). Channeling identity: A study of storytelling in conversations between introverted and extraverted friends. Journal of Research in Personality, 41(5), 1008-1031.https://doi.org/10.1016/j.jrp.2006.12.001

Thorne, A., \& McLean, K. C. (2003). Telling traumatic events in adolescence: A study of master narrative positioning. In C. A. Haden \& R. Fivush (Eds,.) Autobiographical memory and the construction of a narrative self: Developmental and cultural perspectives (pp. 169-185). Lawrence Erlbaum Associates Publishers.

Toolis, E. E., \& Hammack, P. L. (2015). The lived experience of homeless youth: A narrative approach. Qualitative Psychology, 2(1), 50-68. https://doi.org/10.1037/qup0000019
Vélez-Agosto, N. M., Soto-Crespo, J. G., Vizcarrondo-Oppenheimer, M., Vega-Molina, S., \& García Coll, C. (2017). Bronfenbrenner's Bioecological Theory Revision: Moving Culture From the Macro Into the Micro. Perspectives on Psychological Science, 12(5),

900-910. https://doi.org/10.1177/1745691617704397

Viola, L., \& Verheul, J. (2019). The Media Construction of Italian Identity: A Transatlantic, Digital Humanities Analysis of italianità, Ethnicity, and Whiteness, 1867-1920. Identity, 19(4), 294-312. https://doi.org/10.1080/15283488.2019.1681271

Way, N., Santos, C., Niwa, E. Y., \& Kim-Gervey, C. (2008). To be or not to be: An exploration of ethnic identity development in context. New Directions for Child and Adolescent Development, 120, 61-79. https://doi.org/10.1002/cd.216

Weststrate, N. M. (2020). Using Life Story Methods to Capture Cultural-Historical Dimensions of LGBTQ+ Identity Development Across the Generations. To paper in K. C. McLean (Ed.) Cultural Methodologies in Psychology. New York: Oxford Press.

Weststrate, N. M., \& McLean, K. C. (2010). The rise and fall of gay: A cultural-historical approach to gay identity development. Memory, $18(2)$, $225-240$ https://doi.org/10.1080/09658210903153923

Wiernik, B. M. (2019, October 11). Preprint templates. https://doi.org/10.17605/OSF.IO/HSV6A

Wolak, J., \& Peterson, D. A. M. (2020). The Dynamic American Dream. American Journal of Political Science, n/a(n/a). https://doi.org/10.1111/ajps.12522 